\title{
obituary
}

\section{Thomas Adeoye Lambo} O.B.E.

\section{Formerly Assistant Director General, World Health Organization}

Professor Lambo was the most eminent African psychiatrist of his generation. In Nigeria, his name, equally synonymous with psychiatry, was well known to the lay public. Even in Europe and North America, his was the recognisable face of African psychiatry.

His active contribution to psychiatry spanned the period 1953-2004. His early publications described, for the first time, psychiatric disorders as they presented in Africa and as observed by a native African psychiatrist. In his papers Neuropsychiatric Observations in the Western Region (Lambo, 1956) and again in Further Neuropsychiatric Observations in Nigeria (Lambo, 1960), he described the pattern of psychiatric disorders as he saw in Aro and at Ibadan. He confirmed that schizophrenia, affective psychoses and psychoneuroses were prevalent. He was among the first clinicians to observe 'comparatively quick recovery, lack of chronicity, and better therapeutic response generally of schizophrenic patients', which he attributed to the 'favourable social and environmental factors inherent in the community to which the mentally ill are exposed in Africa'. His observations of the relatively good prognosis of schizophrenia were later confirmed by the World Health Organization's International Pilot Study on Schizophrenia. In Psychiatric Disorder among the Yoruba, Lambo, working with the Leightons and others, replicated the Stirling County study. The main finding was that the similarity between pattern and prevalence of psychiatric disorder in Stirling County and the Yoruba were more impressive than the difference; they concluded that in view of the contrast between the cultures and life situations, this is truly remarkable'. The most salient differences were that the Yoruba seemed to have more symptoms, but fewer cases of clearly evident psychiatric disorder and the prevalence of psychiatric disorder was greater among women than men in Stirling County, whereas the reverse was the case among the Yoruba. Also, the Yoruba showed a higher prevalence than in Stirling County of psychiatric symptoms based primarily on organic disorder. This was explained as being due to the greater degree of endemic physical disease and malnutrition among the Yoruba.

Lambo's most innovative development was the Aro village system, which was designed on the Gheel model. Psychiatric patients were boarded out to 4 villages around Aro, accommodating between 200 and 300 patients from a wide geographical area. Lambo believed that those who were boarded out more quickly adapted themselves to their situation than those taken into hospital. He also thought that this was the result of their contact with a settled, tolerant, and healthy environment. The relatives who accompanied the patient witnessed as a result how the doctors regarded mental illness and acquired a more positive attitude towards the patient's illness.

Furthermore, Lambo included traditional doctors and herbalists within the scope of his programme of treatment.

Thomas Adeoye Lambo was born on 29 March 1923 in Abeokuta. But to understand Lambo's achievements, it is helpful to understand that Abeokuta had received a significant number of returned exiles from Freetown, Sierra Leone, from 1840 onwards. These returned exiles had mostly been Africans liberated by the British navy from slaving ships on the high seas, but some were also Africans who had returned from the West Indies, Nova Scotia and Britain after emancipation. These exiles were educated men, artisans and traders. They valued education and jointly with missionaries including Methodists, Baptists and the Church Mission Society built schools and churches in Abeokuta. It was into this vibrant and progressive milieu that Lambo was born. He was educated at one of the mission schools, Baptist Boys' High School and studied medicine in Birmingham, England graduating in 1948. He completed his house jobs at the General Hospital and Midland Nerve Hospital Birmingham. he trained as a psychiatrist at the Maudsley
Hospital (1952-1954) before returning to

Nigeria to set up the Neuropsychiatric Hospital Aro, where he worked until 1963 when he was appointed Professor of Psychiatry at University College Hospital Ibadan. He was later Dean of Medicine (1966-1968) and Vice Chancellor of the University of Ibadan (1968-1971). Lambo joined the World Health Organization in 1971 as Assistant Director General, with special responsibility for the Divisions of Mental Health, Non-communicable diseases, Therapeutics \& Prophylactic Substances and Health Manpower Development. He later became Deputy Director of the World Health Organization in 1973, and worked in that capacity until 1988. He was honoured by many institutions during his life, including appointment to the Pontifical Academy of Sciences (1974), Haile Selassie Africa Research Award (1970) and honorary doctorates from University of Benin, University of Birmingham, Kent State University, Université d'Aix-Marseille, Long Island University, and Catholic University of Louvan. He was awarded Nigeria's highest honour, the National Merit Award.

Lambo's most enduring legacies are the Neuropsychiatric Hospital Aro, which he built, and the Department of Psychiatry at the University of Ibadan where he was the foundation Professor and Head of Department. Aro remains the most important and prestigious psychiatric hospital in Nigeria. The Department of Psychiatry in Ibadan continues to make significant contributions to our understanding of psychiatric disorders in Nigeria and Africa, but, perhaps most importantly, continues to inspire young students to make psychiatry their choice of career. Many Ibadan graduates choose psychiatry and have in their turn developed academic departments within other Nigerian universities and elsewhere.

This is truly evidence that Lambo's dedication to service, his energy and drive, his exceptional vision and innovative spirit served as a model for many of us.

His wife, Dinah Violet Adams, whom he married in 1945, and their 3 sons survive him.

Femi Oyebode 